\title{
Technical note: Quantification of caseins from a crude extract of mammary epithelial cells
}

\author{
Eric Chanat ${ }^{*}{ }^{1}$ and Frédéric Dessauge ${ }^{*} \dagger$ \\ *INRA, UMR1348 PEGASE, F-35590 Saint-Gilles, France \\ †Agrocampus Ouest, UMR1348 PEGASE, F-35000 Rennes, France
}

\begin{abstract}
En masse secretion of milk proteins, notably the caseins in the form of casein micelles, is a unique feature of the milk-secreting mammary epithelial cell. Caseins are therefore specific markers of these cells and constitute an ideal tool to monitor their differentiation, as well as functional status, during the development of the gland. To use them as such, a reliable method for quantitative analysis of the caseins from mammary cells or tissue is needed. Here we show that the caseins are heat-stable, a feature that leads to their complete extraction from a complex cellular extract by boiling. This allows for high enrichment and direct analysis of the caseins, even when they are poorly expressed in the starting material.
\end{abstract}

Key words: casein, lactation, mammary gland, proteins, secretory pathway

\section{Technical Note}

During lactation, mammary epithelial cells (MEC) secrete large quantities of milk proteins, notably caseins. Caseins $\left(\alpha_{\mathrm{S1}^{-}}, \alpha_{\mathrm{S2}^{-}}, \beta-\right.$, and $\kappa_{-} \mathrm{CN}$ in most species) are the main milk-specific proteins (for review see (Huppertz, 2013), and therefore specific markers of functional MEC. Quantitation of the expression of casein genes has been essential to the understanding of the cellular and molecular events that underlie the differentiation of the mammary gland. It appears, however, that mRNA levels do not systematically reflect the amount of the corresponding proteins within the tissue. Alternatively, estimating the degree of differentiation of the mammary cells via the amount of caseins in crude cell extracts could be challenging, especially at the onset of their expression. Having a simple and reliable biochemical method for assaying caseins from

Received October 25, 2017.

Accepted December 17, 2017.

${ }^{1}$ Corresponding author: eric.chanat@inra.fr a tissue or cell preparation would be highly valuable, especially at the time they are expressed at a low level. With this aim, and knowing that caseins have been described as unfolded (or rheomorphic) proteins (Thorn et al., 2015) and therefore are most likely heat-stable, a method was developed to enrich the caseins from total cell extracts.

A heat-stable protein fraction (HSF) can be prepared either directly from cells in culture (cell lines or primary cultures), from a cell suspension, or from tissue samples (fresh or frozen). The first step, when starting from tissue, is to disrupt the HSF with a tissue homogenizer before the extraction of the proteins of interest. After homogenization of fresh tissue samples, it is advisable to prepare a postnuclear supernatant (PNS).

For the experiments described in the present report, mammary gland tissue samples were collected from either lactating bovine (Normande Holstein crossbreed, mid-lactation) mammary tissue or from nonlactating mid-gestation Alpine goats. Goats were raised at the experimental farm of Méjusseaume INRA-Rennes (France). They were slaughtered under general anesthesia with subsequent euthanasia (Rompun, i.v. 1 $\mathrm{mL}$; Dolethal, i.v. $25 \mathrm{~mL}$, Vetoquinol, Lure, France) and the mammary gland was removed from animals at autopsy for sampling. Cows were euthanized at the slaughterhouse of Gallais Viande (Montaubande-Bretagne, France) following standard commercial practices. The mammary glands were collected at time of slaughter and immediately transported on ice to the laboratory to be sampled according to further analysis. Wistar rats were raised in our institute (research unit "Nutrition et Régulation Lipidiques des Fonctions Cérébrales, INRA, Jouy-en-Josas, France) and females at mid-lactation were euthanized by decapitation. Animal welfare and handling were in accordance with the guidelines of the European Community for the care and use of animals in research (Directive no. 86/609/EEC). These experiments were approved by the Ministry of Research and Technology (agreement no. A78725). The principal investigator owns an accreditation for animal experimentation (license no. 78-62). 
For the preparation of tissue powder from frozen tissue samples stored at $-80^{\circ} \mathrm{C}$, tissue pieces were first transferred to liquid nitrogen. Tissue fragments $(\approx 10$ $\mathrm{g})$ were then crushed for $\approx 10 \mathrm{~s}$ using a tissue grinder (tissue grinder IKA model A 11 basic analytical mill, Staufen, Germany). The resulting powder was immediately stored in liquid nitrogen.

For the preparation of tissue homogenate from fresh tissue, all steps were performed at $4^{\circ} \mathrm{C}$. Tissue pieces $(\approx 10 \mathrm{~g})$ taken from euthanatized animals were immediately put in ice-cold $0.25 \mathrm{M}$ sucrose. Samples were cut into several 5 to $10 \mathrm{~mm}^{3}$ pieces, and any remaining connective tissue, muscle, and lymph nodes were removed. Tissue pieces were weighed and finely chopped with surgical scissors $\left(1-2 \mathrm{~mm}^{3}\right.$ fragments). Tissue fragments were washed twice with ice-cold $0.25 \mathrm{M}$ sucrose for 10 min at $4^{\circ} \mathrm{C}$ and once with ice-cold $0.25 \mathrm{M}$ sucrose in $\mathrm{HMg}$ buffer $\left\{10 \mathrm{~m} M\right.$ Hepes-KOH pH 6.8, $5 \mathrm{~m} M \mathrm{MgCl}_{2}$ [or $\left.\left.\mathrm{Mg}(\mathrm{OAc})_{2}\right]\right\}$ supplemented with phenylmethylsulfonyl fluoride (PMSF; $40 \mu \mathrm{L} 250 \mathrm{mM}$ PMSF for 100 $\mathrm{mL}$ ). Tissue fragments were then resuspended in $30 \mathrm{~mL}$ of $0.25 \mathrm{M}$ sucrose-HMg-PMSF supplemented with 100 $\mu \mathrm{L}$ of protease inhibitor cocktail (Sigma-Aldrich, St. Louis, MO). Tissue suspension (1/4 to $1 / 3$ at a time) was transferred into the tissue grinder (Potter-Elvehjem tissue grinder with Teflon pestle type AA, $10 \mathrm{~mL}$, or B, $30 \mathrm{~mL}$ capacity; Thomas Scientific, Swedesboro, NJ) and homogenized using the ribbed Teflon pestle driven by an overhead stirrer motor at the lowest speed for 3 to 5 strokes (use low speed to avoid warming of the suspension; if direct homogenization with the Teflon pestle is too difficult, short low power prehomogenization with a Polytron homogenizer could be performed). The resulting homogenate was filtered and its volume measured.

For preparation of a PNS, the homogenate was distributed into 2 centrifuge tubes, carefully layered with $2 \mathrm{~mL}$ of $\mathrm{HMg}$ buffer, and centrifuged in a swing-out rotor at $1,200 \times g$ for $10 \mathrm{~min}$ at $4^{\circ} \mathrm{C}$ with the brake on to pellet cellular debris and nuclei. The resulting supernatant is referred to as PNS. If required, the thin layer of cream that might float above the supernatant was removed as much as possible by aspiration with a Pasteur pipette. The PNS was poured into a $50-\mathrm{mL}$ tube, gently mixed by inverting the tube, and aliquoted for storage at $-80^{\circ} \mathrm{C}$.

For preparation of HSF from cultured cell lines or primary cell cultures, culture dishes were placed on an ice-chilled surface (the rapid cooling of the cells stops intracellular transport and secretion, slows metabolic activity, and potential protein degradation after cell lysis), the culture medium was removed and cells were washed 3 times with ice-cold Tris-buffered saline, the last wash containing $0.5 \mathrm{~m} M$ PMSF. Cells were layered with $1 \mathrm{~mL}$ (volume for a 3.5-cm diameter dish or well) of $1 \times$ Tris $\mathrm{NaCl}$ Tween EDTA (TNTE; $20 \mathrm{mM}$ Tris- $\mathrm{HCl}, \mathrm{pH}$ 7.4, $150 \mathrm{~m} M \mathrm{NaCl}, 0.3 \%$ Tween-20, 20 $\mathrm{m} M$ EDTA from 0.5 $M$ EDTA, pH 8.0) supplemented with $0.5 \mathrm{~m} M$ PMSF and incubated on ice for 15 to 30 min. The cell lysate was collected into a microtube or centrifuge tube.

For the preparation of a HSF from tissue powder, an appropriate amount of powder was taken into a microtube, $20 \mathrm{mg}$, and $2 \mathrm{~mL}$ of $1 \times$ TNTE with PMSF was added. The suspension was homogenized using a plastic pestle for microtubes or a small volume PotterElvehjem tissue grinder driven by an overhead stirrer motor at the lowest speed. Samples were incubated with gentle mixing for 30 to $45 \mathrm{~min}$ at $4^{\circ} \mathrm{C}$.

For preparation of HSF from mammary tissue homogenate or PNS, the relevant volume of tissue lysate was distributed into microtubes or centrifuge tubes and diluted if required (it is recommended $10 \mathrm{mg}$ of tissue/mL final volume). In concentrated homogenates, organelles can aggregate, which may result in modified protein precipitation during boiling. To decrease the salt concentration and improve the yield, it is recommended to dilute the cell lysate 5 to 10 times in low-salt buffer or with $\mathrm{H}_{2} \mathrm{O}$. Two times concentrated TNTE was added $(1: 1, \mathrm{vol} / \mathrm{vol})$ and samples were incubated with gentle mixing for 30 to $45 \mathrm{~min}$ at $4^{\circ} \mathrm{C}$.

To proceed to preparation of the HSF, a small hole was first made in tube caps. The tubes were then boiled for $5 \mathrm{~min}$ and centrifuged for $15 \mathrm{~min}$ at top speed in a microtube centrifuge $(\approx 13,000 \times g)$ or equivalent, at room temperature. The supernatant, referred to as HSF, was stored on ice. The pellet was resuspended in $1 \times \operatorname{TNTE}(1 / 2-1 / 1$ of starting volume), vortexed vigorously at room temperature and centrifuged as above. The resulting supernatant was pooled with the HSF (this washing step is not mandatory). The pellet (heat-unstable protein fraction; HUF) was solubilized in SDS-PAGE lysis buffer (as most cellular proteins are recovered in the HUF after boiling, analyzing the complete HUF might lead to saturation of the gel; it is therefore recommended to analyze only $10-50 \%$ of the HUF). In standard conditions and using mini-gels, a maximum of $20 \mu \mathrm{g}$ of protein was loaded per lane. Proteins in the HSF were precipitated using trichloroacetic acid, washed with ice-cold ethanol/ether solution $(1 / 1, \mathrm{vol} / \mathrm{vol})$, resuspended in SDS-PAGE lysis buffer, and boiled immediately for $5 \mathrm{~min}$. Samples were either stored at $-20^{\circ} \mathrm{C}$ or immediately subjected to SDSPAGE followed by Coomassie Blue (Bio-Rad, Marnesla-Coquette, France) staining or Western blot, as previously described (Le Parc et al., 2010). Note that for the 
analysis of bovine proteins, immunoblotting membranes were not treated with bovine milk or BioRad (Hercules, CA) blocking reagent. Monoclonal antibodies (Dupont et al., 2011) against bovine $\alpha_{\mathrm{S} 1}-\mathrm{CN}$ (f19-37 in Dupont et al., 2011), $\alpha_{S_{2}} \mathrm{CN}$ (f16-35), $\beta-\mathrm{CN}$ (f133-150), and k-CN (f98-115) were all used at 1:250 dilution. Rabbit polyclonal antibodies against goat caseins were used at 1:5,000 dilution (Chanat et al., 1999).

Here, the demonstration of the heat-stability of the caseins is first shown for the archetypal bovine caseins (Figure 1). After boiling in TNTE and centrifugation, most of the proteins from lactating bovine mammary tissue were recovered in the pellet; however, it was clear that certain proteins were only found in the supernatant (Figure 1; i.e., they were thermostable). This was obviously the case for the main band at $\approx 70 \mathrm{kDa}$ and for several proteins between 23 and $35 \mathrm{kDa}$, as these latter proteins were found to include the caseins (Figure 1). Indeed, each of the caseins was largely, if not exclusively, recovered in the supernatant after boiling in TNTE and centrifugation, demonstrating that bovine caseins are heat-stable.

Of note is the fact that the aggregation of the caseins starts quite early in the biosynthetic pathway (Farrell et al., 2006; Le Parc et al., 2014), and a substantial part of caseins are in the form of casein micelles within the mammary tissue (Farrell et al., 2006). Casein micelles are very large structures that exhibit a high sedimentation rate and can be easily sedimented by centrifugation. As the present assay was based on the fractionation of heat-stable proteins from heat-unstable proteins via sedimentation, it was of utmost importance to ensure that conditions of incubation in TNTE destabilized the casein micelle structure and allowed the release of caseins before the centrifugation step. This has been previously demonstrated for rat and mouse caseins (Bouguyon et al., 2006; Le Parc et al., 2010). It was confirmed in the present study for bovine

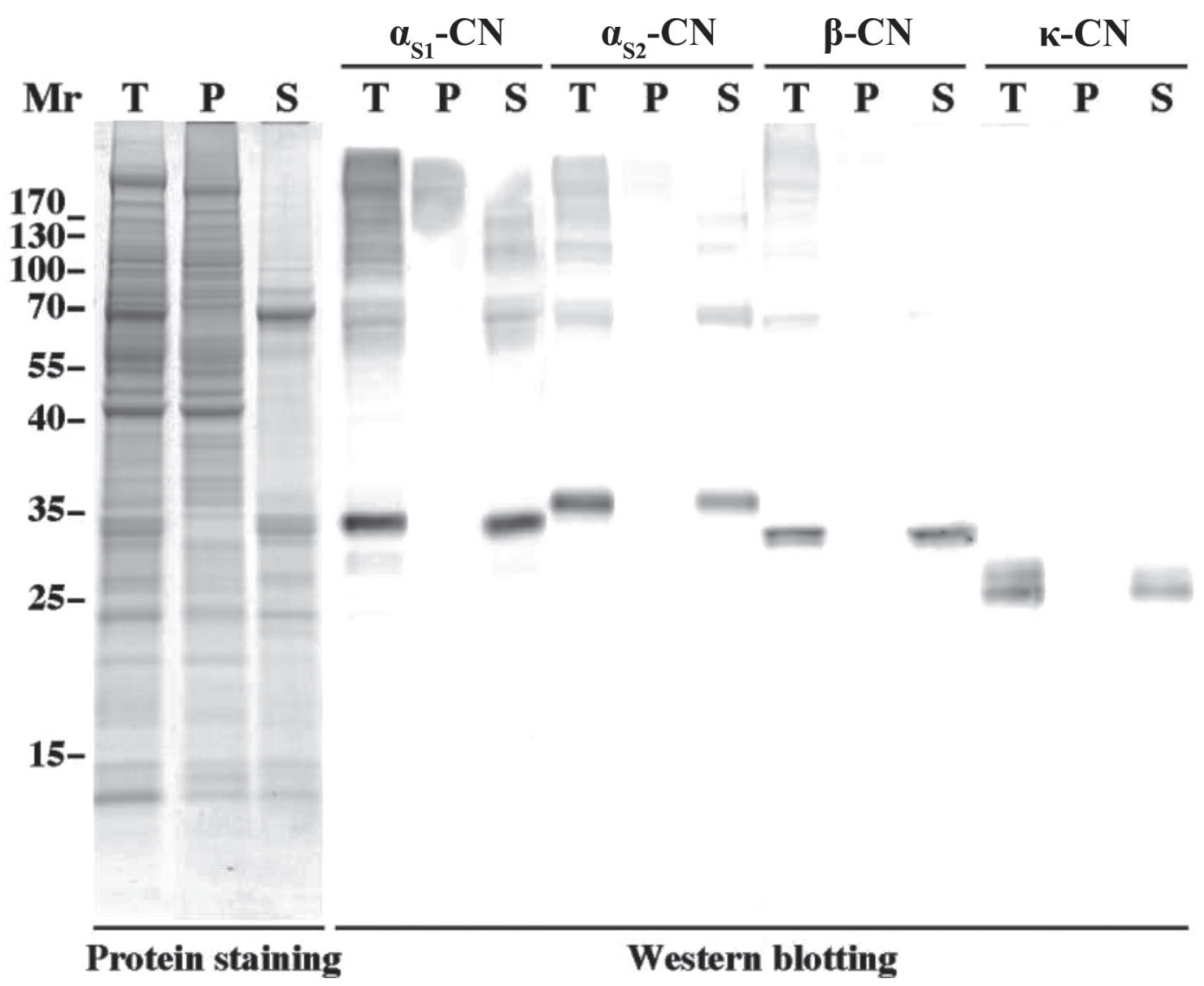

Figure 1. Bovine caseins are heat-stable. Bovine mammary tissue from a lactating animal was homogenized and a postnuclear supernatant (PNS) was prepared. An aliquot of the PNS was diluted and incubated in Tris $\mathrm{NaCl}$ Tween EDTA and boiled. After centrifugation at 100,000 $\times$ $g$ for $1 \mathrm{~h}$ at $4^{\circ} \mathrm{C}$, the supernatant $(\mathrm{S})$ and the pellet $(\mathrm{P})$, as well as the PNS (T, total), were analyzed via SDS-PAGE followed by either Coomassie Blue staining (protein staining) or Western blotting with antibodies against each casein. Relative molecular masses (Mr; kDa) are indicated. 

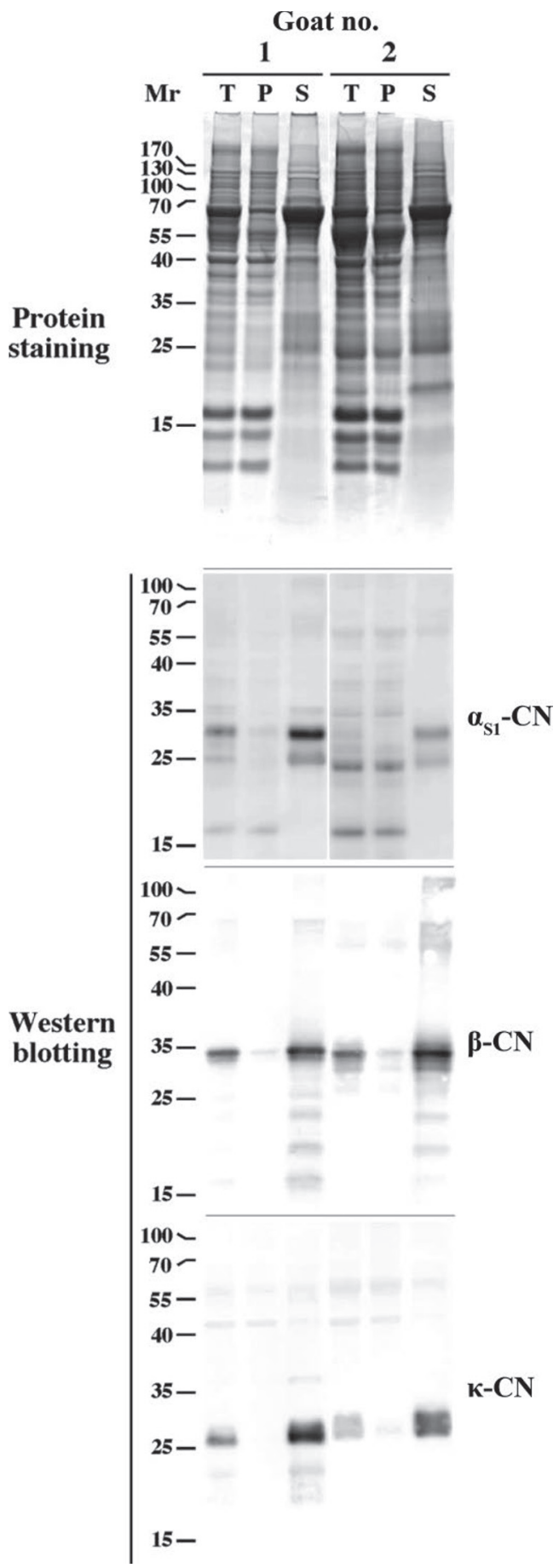

Figure 2. Heat-stability is a powerful means for the enrichment and the direct analysis of caseins. Goat mammary tissue obtained from animals at mid-gestation was snap frozen in liquid nitrogen and homogenized. An aliquot of the homogenate was diluted and incubated in Tris NaCl Tween EDTA, and boiled. After centrifugation for $15 \mathrm{~min}$ at top speed in a microtube centrifuge $(\approx 13,000 \times g)$ or equivalent at room temperature, the pellet $(\mathrm{P})$, the supernatant $(\mathrm{S})$ prepared from 5 volumes of homogenate, and the homogenate $(\mathrm{T})$ were analyzed via SDS-PAGE followed by either Coomassie Blue staining (protein staining) or Western blotting with antibodies against $\alpha_{\mathrm{S1}^{-}}, \beta-$, or $\kappa$-CN. The gels from 2 independent experiments are shown. Relative molecular masses $(\mathrm{Mr} ; \mathrm{kDa})$ are indicated. caseins, as the HSF from bovine tissue was fractionated by centrifugation at $110,000 \times g$ for $1 \mathrm{~h}$ at $4^{\circ} \mathrm{C}$ instead of $13,000 \times g$ used in standard conditions.

The use of the mouse MEC line HC11, in which only the immature, nonphosphorylated form of $\beta$-casein is detected (Pauloin et al., 2010), and of metabolic labeling of rat mammary gland explants allowed us to demonstrated that immature forms of the caseins are heat-stable, similar to the mature forms (data not shown). Heat-stability is therefore an intrinsic property of the caseins across species and is independent of their post-translational modifications.

To further confirm using heat-stability of the caseins in the study of the mammary gland at the tissue level, we subjected pieces of goat mammary parenchyma collected at mid-gestation to a standard HSF preparation. At that stage, the mammary gland starts to express casein transcripts, but the amount of the corresponding proteins is obviously low. We therefore analyzed HSF prepared from 5 times the amount of protein used in standard conditions (i.e., $100 \mu \mathrm{g}$ ). Certain protein bands were found in higher amounts in the HSF compared with those present in total homogenate (Figure 2; compare the amount of the $67 \mathrm{kDa}$ band in $\mathrm{T}$ and S). As shown by Western blotting, this allows the clear detection of the caseins, even within samples containing little of the protein in total homogenate (Figure 2; see $\alpha S_{1^{-}}$and $\kappa$-CN in sample 2). The heat-stable protein at $\approx 18000 \mathrm{kDa}$ is most likely $\beta-\mathrm{LG}$, as it co-migrated with a band detected by antibodies against this whey protein (data not shown).

In summary, these data demonstrate that heatstability is a key feature of the caseins that allows their enrichment in total cell extract by boiling and highly facilitates their analysis.

\section{ACKNOWLEDGMENTS}

We are grateful to Didier Dupont (INRA-Agrocampus, Rennes, France) for antibodies against bovine caseins.

\section{REFERENCES}

Bouguyon, E., C. Beauvallet, J. C. Huet, and E. Chanat. 2006. Disulphide bonds in casein micelle from milk. Biochem. Biophys. Res. Commun. 343:450-458.

Chanat, E., P. Martin, and M. Ollivier-Bousquet. 1999. Alpha(S1)casein is required for the efficient transport of beta- and kappacasein from the endoplasmic reticulum to the Golgi apparatus of mammary epithelial cells. J. Cell Sci. 112:3399-3412.

Dupont, D., A. Johansson, S. Marchin, O. Rolet-Repecaud, S. Marchesseau, and J. Leonil. 2011. Topography of the casein micelle surface by surface plasmon resonance (SPR) using a selection of specific monoclonal antibodies. J. Agric. Food Chem. 59:8375-8384. 
Farrell, H., Jr., E. Malin, E. Brown, and P. Qi. 2006. Casein micelle structure: What can be learned from milk synthesis and structural biology? Curr. Opin. Colloid Interface Sci. 11:135-147.

Huppertz, T. 2013. Chemistry of the caseins. Pages 135-160 in Advanced Dairy Chemistry. Vol. 1A: Proteins: Basic Aspects. 4th ed. P. L. H. McSweeney and P. F. Fox, ed. Springer Science+Business Media, New York, NY.

Le Parc, A., E. Honvo Houéto, N. Pigat, S. Chat, J. Leonil, and E. Chanat. 2014. The membrane-associated form of as1-casein interacts with cholesterol-rich detergent-resistant microdomains. PLoS One 9:e115903.
Le Parc, A., J. Leonil, and E. Chanat. 2010. AlphaS1-casein, which is essential for efficient ER-to-Golgi casein transport, is also present in a tightly membrane-associated form. BMC Cell Biol. 11:65.

Pauloin, A., S. Chat, C. Pechoux, C. Hue-Beauvais, S. Droineau, L. Galio, E. Devinoy, and E. Chanat. 2010. Oleate and linoleate stimulate degradation of beta-casein in prolactin-treated HC11 mouse mammary epithelial cells. Cell Tissue Res. 340:91-102.

Thorn, D. C., H. Ecroyd, J. A. Carver, and C. Holt. 2015. Casein structures in the context of unfolded proteins. Int. Dairy J. 46:2-11. 